\title{
O estudo da sexualidade humana nos cursos de formação de psicólogos
}

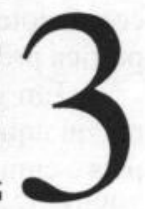

Ana Cláudia Bortolozzi Maia*

\section{RESUMO}

Considerando que a Educação Sexual é um processo amplo, histórico e social inerente aos relacionamentos humanos e evidente em todos os aspectos de qualquer profissão, hoje é uma necessidade que se discuta e se reflita sobre este tema nos cursos de formação profissional (graduação). A Psicologia, como qualquer outra área da saúde, deve ser uma ciência fundamental para oferecer recursos metodológicos, teóricos e técnicos para se trabalhar as questões da sexualidade humana em diferentes instituições sociais. $\mathrm{O}$ presente artigo relata uma proposta de duas disciplinas regulares e um estágio sobre a sexualidade humana, no curso de formação de Psicólogos da UNESP/Campus de Bauru/SP.

\section{INTRODUÇÃO}

Atualmente, muito se discute sobre a sexualidade humana, seja com fins educativos, esclarecedores ou repressivos. Em tempos de AIDS, porém, já não é

* Psicóloga clínica; Professora Mestre do Curso de Psicologia, lotada junto ao Departamento de Psicologia da UNESP/ Campus de Bauru/SP.

Recebido em 05.11.99

Aprovado em 15.11.99 
mais possível deixar este tema como algo secundário. A mídia, a literatura e a comunidade, tem oferecido espaço para a discussão das questões relativas à sexualidade de maneira enfática. A universidade pode usufruir dos avanços da pesquisa e do interesse de novos pesquisadores nesta área contribuindo para o esclarecimento das questões mais polêmicas. $\mathrm{O}$ que antes pouco se discutia, hoje torna-se leitura corrente entre leigos e profissionais da área.

Não são poucos, portanto, os profissionais de diferentes áreas que se interessam pelas questões da sexualidade. Professores, enfermeiros, médi$\cos$, fisioterapeutas e psicólogos acolhem as questões da sexualidade na sua prática profissional.

Em geral, a educação sexual tem sido oferecida às crianças e jovens em qualquer comunidade, objetivando prepará-los para exercerem seus papéis e cumprirem regularmente suas funções sexuais na sociedade (Vitiello, 1986). Todos nós estamos submetidos aos preceitos da educação sexual, seja através das regras, mitos, tabus, seja por crendices, ou pelas atitudes sociais que quase sempre regem nossas ações e sentimentos na sociedade; estas ações são marcadas pela repressão sexual.

Sendo a sexualidade humana expressão de um processo histórico, os indivíduos tendem a exercer um papel social e sexual determinado por diferentes dimensões: biológica, psicológica e social, vivenciadas diferentemente em cada realidade histórico-cultural. Falar em educação sexual, requer uma reflexão sobre um processo amplo e constante que é mais que o ato de informar, de orientar e de aconselhar, pois refere-se ao processo de formar os indivíduos pelo conhecimento dos aspectos biológicos, psicológicos, sociais e éticos (Fagundes, 1992; Vitiello, 1992).

Assim, muito dos comportamentos e sentimentos com relação a nossa própria sexualidade e a de outros, advém de influências de um processo de educação sexual que remonta à gravidez. Mesmo que não percebamos estamos sempre em contato social e este influencia nossas acepções de comportamento moral, do que é permitido, digno, correto, etc. o que nos limita, muitas vezes, quanto ao conhecimento e à vivência de uma sexualidade sadia, livre de preconceitos e tabus. Assim, a influência repressiva que o processo de educação sexual exerce sobre nossas vidas, pode, muitas vezes, bloquear a construção do conhecimento dos aspectos biológicos, das representações psíquicas ou sobre as condutas sociais relativas à sexualidade humana. Essa educação sexual permeia nossa vida constantemente e com as novas experiências podemos refletir sobre ela e também alterá-la.

A transformação da educação sexual historicamente existente é, sem dúvida, uma tarefa difícil, mas não impossível. Para tal, é preciso que trabalhemos, não no sentido restrito de informar ou aconselhar, mas no sentido de também sermos agentes ativos da educação sexual. Uma orientação sexual sistematizada pode influenciar e fazer parte da educação sexual dos indivíduos em diferentes instituições sociais (família, escola, empresa, comunidade, creches, hospitais, etc.) possibilitando a eles refletirem sobre este processo em que vivemos. 
Os programas de orientação sexual, atualmente, podem eventualmente servir como processos de "des-educação", contrariando os objetivos ideais, se contarem com pessoas despreparadas, imaturas, preconceituosas, ou então basearem-se em programas inadequados, com conteúdo e abordagens inadequadas, em que se reduz a sexualidade à mera genitalidade. Para evitar este desastre, é preciso considerar que não basta garantir um espaço para se falar em sexualidade, mas sim que este espaço seja de qualidade e acima de tudo, prime pela ética. A educação sexual deve ser, portanto, um exercício de sabedoria, de reflexão; deve ser um espaço aberto em que especialistas, educadores e psicólogos, possam expandir os conhecimentos e as informações dentro de um processo amplo na formação de cidadãos mais conscientes e reflexivos e, por isso mesmo, como acredita Goldberg (1988) mais livres e mais voltados para a transformação da sociedade vigente.

Todos nós somos responsáveis - e alvos - de processos de educação sexual em nossa sociedade: família; escola (professores, funcionários, direção) e a comunidade em geral. É contando com a possibilidade de revermos nossos processos de educação sexual que programas de orientação sexual vêm sendo oferecidos aos jovens e a outros grupos e segmentos da população visando refletir sobre temas como a sexualidade e a cultura (papéis sexuais, mitos, repressão sexual), saúde sexual (métodos anticoncepcionais, AIDS), relacionamentos (amor, erotismo, homossexualismo), etc.

O responsável por um programa de orientação sexual sistematizado pode ser, portanto, qualquer pessoa que esteja preparada, que seja ética e que saiba articular a vontade de buscar informações adequadas para as pessoas refletirem, criticamente, sobre os temas da sexualidade. Dentre os profissionais da área da saúde que podem se tornar agentes de educação sexual voltados para a orientação sexual adequada da população, encontram-se os psicólogos, embora em geral, os cursos de formação deste profissionais, assim como os da medicina, enfermagem, magistério, não têm oferecido suporte curricular que os preparem para esta tarefa. ${ }^{1}$

O psicólogo deve trabalhar na sua formação para ampliar seus conhecimentos sobre o tema, discutir questões polêmicas sobre os preconceitos e os tabus; deve estar aberto para compreender a dinâmica da sexualidade, revendo o processo de educação sexual que traz consigo. Foi pensando nestes aspectos, que o curso de formação de Psicólogos da UNESP, Campus de Bauru/SP, tem oferecido aos seus alunos a oportunidade de estudarem a sexualidade humana (não somente em nível informativo), refletindo sobre estas questões e buscando na prática a articulação teórica dos conhecimentos acumulados pela comunidade científica com as necessidades sociais.

1. Embora não seja uma prática comum, hoje alguns profissionais têm se preocupado com esta questão e desenvolvido iniciativas de implantação de Disciplinas de Sexualidade Humana nos cursos da área da saúde como Medicina, Enfermagem, Ciências Biológicas, Pedagogia, Educação Física, Psicologia, e outras. Ver: FAGUNDES (1996) e também SERAPIÃO \& SILVA (1996). 
O curso de Formação de Psicólogos da UNESP/Campus de Bauru/SP tem duração de 5 anos no período integral e duração de 6 anos no período noturno. Na grade curricular, regular (disciplinas obrigatórias) o curso conta com duas disciplinas específicas acerca da sexualidade: "Educação e Desenvolvimento Sexual" e "Questões Especiais da Sexualidade Humana", cada uma com duração de um semestre (17 aulas de 4 créditos) e recentemente vêm implantando uma proposta de Estágio. A seguir apresentam-se os programas propostos para estas disciplinas:

\section{1) Disciplina: "EDUCAÇÃO E DESENVOLVIMENTO SEXUAL"}

Ementa: Esta disciplina deverá garantir ao aluno condições básicas de conhecimento do Desenvolvimento da Sexualidade nos seus aspectos biológicos, psicológicos e sociais. Para tal, o conteúdo deverá abordar questões que apresentem uma dimensão ampla da história e desenvolvimento sexual do ser humano além de ampliar o conceito de sexualidade, procurando desmistificá-lo nos seus tabus e preconceitos. Por fim o curso prevê a formação dos profissionais para que sejam capazes de serem agentes de educação sexual com ética e responsabilidade.

\section{Objetivos}

a) Ampliar a noção de sexualidade e de educação sexual do homem moderno;

b) Discutir os aspectos históricos da sexualidade humana e conhecer os fundamentos biológicos da sexualidade humana nas suas questões básicas;

c) Refletir sobre o comportamento sexual no desenvolvimento humano: infantil, adolescente, na terceira idade e de pessoas com deficiência;

d) Analisar criticamente a literatura atual proposta para a orientação/ educação sexual infantil, púbere e adulta;

e) Identificar e discutir sobre as perspectivas e responsabilidades da educação sexual nas diferentes instâncias sociais: família, escola e comunidade;

\section{Conteúdo}

UNIDADE I: Educação, Sexualidade e Sociedade

- Educação Sexual e Sexualidade;

- Identidade e Papéis sexuais;

- Mitos, crendices e Tabus sexuais;

- Repressão Sexual. 
UNIDADE II: História da Sexualidade Humana

- Origens e funções da Sexualidade;

- Processo evolutivo da hominização e suas repercussões sobre a sexualidade.

UNIDADE III: Fundamentos biológicos da sexualidade humana

- Anatomia e Fisiologia da Resposta Sexual;

- Anatomia e Fisiologia da Reprodução Sexual (fecundação; menstruação);

- Planejamento Familiar: anticoncepção e gravidez.

UNIDADE IV: Comportamento sexual no desenvolvimento humano

- Sexualidade na Infância;

- Sexualidade na Adolescência;

- Sexualidade na Terceira Idade;

- Sexualidade e Deficiências.

UNIDADE V: Perspectivas e responsabilidades da educação sexual

- Educação sexual x Orientação sexual;

- Agentes e Instituições responsáveis;

- A sexualidade na Escola;

- Planejamento de Programas de Orientação Sexual.

\section{Atividades Práticas da Disciplina}

a) Análise crítica de Livros de Educação Sexual: infantil, adolescente ou adulto: o aluno deverá realizar a leitura de um livro que se diz destinado à educação sexual, à luz da teoria, desenvolvendo uma análise crítica do material lido.

b) Perspectivas e responsabilidade da educação sexual: o aluno deverá ser capaz de elaborar (planejar) um Projeto de Orientação Sexual pensando em objetivos, metodologia, população participante, materiais e carga horária.

\section{Metodologia}

As aulas serão expositivas e discussivas. Vários recursos metodológicos serão utilizados para melhorar o aproveitamento do conteúdo (transparências, vídeos, cartazes, materiais didáticos específicos, como peças anatômicas e diferentes dinâmicas). $\mathrm{O}$ curso priorizará o debate e a reflexão. Para tal, é fundamental a participação dos alunos visando um curso mais dinâmico e proveitoso.

\section{Avaliação do conteúdo}

As avaliações deverão ocorrer ao longo do semestre através de provas do conteúdo teórico e o cumprimento das atividades práticas (análise e apresentação dos livros sobre educação sexual analisados e o planejamento de um programa de orientação sexual). 


\section{2) Disciplina: "QUESTÕES ESPECIAIS DA SEXUALIDADE HUMANA"}

Ementa: Esta disciplina deverá garantir ao aluno condições básicas para discutir, refletir e analisar situações especiais dos relacionamentos humanos na vivência da sexualidade. Para tal, o conteúdo deverá abordar questões que apresentem uma dimensão reflexiva, à luz de uma investigação da realidade, considerando que os aspectos de educação e desenvolvimento sexual no prisma biológico, psicológico e social já devem ter sido apreendidos na disciplina anterior.

\section{Objetivos}

a) Conhecer basicamente conceitos e exemplos de Disfunções Sexuais;

b) Refletir sobre os aspectos técnicos e éticos da Terapia Sexual;

c) Pesquisar (investigar, analisar e sintetizar) temas importantes da Sexualidade Humana de interesse geral.

d) Garantir uma postura ética e sem preconceitos sobre temas polêmi$\cos$ da sexualidade na atualidade.

\section{Conteúdo:}

UNIDADE I: Manifestação da sexualidade

- Enamoramento e Amor;

- Erotismo e Pornografia;

- Disfunções Sexuais;

- Terapia Sexual;

- Práticas sexuais (masturbação, sexo oral e sexo anal);

- Parafilias (exibicionismo, vouyerismo, sadismo, masoquismo, travestismo, fetichismo, pedofilia).

UNIDADE II: Temas especiais em sexualidade

- Abortamento;

- Machismo e Feminismo;

- Casamento e Fidelidade;

- Doenças Sexualmente Transmissíveis/AIDS;

- Homossexualismo Feminino e Masculino;

- Sexualidade e Drogas;

- Sexualidade, Artes e a Mídia;

- Sexualidade e Religião;

- Sexualidade e gravidez;

- Assédio Sexual;

- Pornografia;

- Prostituição. 


\section{Atividades Práticas da Disciplina}

Cada aluno deverá estudar um dos temas da segunda unidade, garantindo uma reflexão teórica bem como investigar na comunidade aspetos práticos relacionados ao tema com visitas, entrevistas, questionários, filmagens, etc. discutindo o estudado com os demais alunos na forma de Seminários.

\section{Metodologia}

As aulas serão expositivas e discussivas, com responsabilidade do professor e alunos em Seminários dos temas específicos ${ }^{2}$. O curso priorizará debates e reflexões críticas da realidade analisada.

\section{Avaliação do conteúdo}

A Unidade I será avaliada com Provas e a Unidade II com Seminários (apresentação e texto escrito). A nota final será a média das duas notas das Unidades, considerando a freqüência e participação em aula.

\section{3) Estágio: EDUCAÇÃO SEXUAL}

Objetivo: O projeto de estágio tem por objetivo treinar profissionais, do Curso de Formação de Psicólogos, para serem educadores e pesquisadores na área da sexualidade humana. O objetivo básico é que o aluno possa colocar em prática os conhecimentos adquiridos no curso teórico (Disciplinas "Desenvolvimento e Educação Sexual" e "Questões especiais da sexualidade humana"), elaborando e intervindo junto à comunidade com projetos de orientação sexual, bem como relacionando-os às atividades de pesquisa.

\section{Área de conhecimento e Campo de aplicação}

A proposta deste estágio refere-se a aplicação dos conhecimentos teóricos na área da sexualidade humana, nas suas dimensões psicológicas e educacionais, em todas as instâncias sociais. Neste sentido, poder-se-á ser trabalhado questões emergentes da sexualidade em atendimentos individuais de orientação, grupos de orientação sexual em instituições sociais, visando esclarecimento do desenvolvimento da sexualidade nos seus aspec-

2. O Seminário, definido como 'grupo de estudos em que se debate a matéria exposta por cada um dos participantes', prevê o acompanhamento do docente responsável na preparação do mesmo, após a análise da literatura e de pesquisas de campo realizadas pelos alunos do tema escolhido. Vários são os recursos metodológicos elaborados para garantir a participação de todos em cada seminário. 
tos biológicos e psicossociais, a fim de contribuirmos para a formação de cidadãos mais livres de tabus e sexualmente mais responsáveis. Outrossim, este estágio prevê, juntamente com as atividades de atendimento, o registro das atividades em pesquisas, que poderão auxiliar no acúmulo de informações científicas da área para futuros projetos de intervenção.

\section{Metodologia de Ensino}

a) Números de Vagas: a proposta de estágio prevê número de até 10 vagas, sendo que os alunos poderão trabalhar em duplas, subgrupos ou todo o grupo dependendo da atividade, atendimento, projetos de intervenção e pesquisa, discussão de casos em supervisão.

b) Carga Horária: o Estágio terá 12 créditos semanais o que corresponde a um total de 204 horas/aula.

c) Desenvolvimento das Etapas do Estágio: ao longo do Estágio, o aluno deverá: aprofundar os aspectos teóricos da literatura disponível através de leituras e fichamentos exigidos pelo supervisor; participar das discussões de casos, compartilhando propostas de atuação, com outros estagiários de diferentes áreas (outros estágios) da própria demanda do Centro de Psicologia Aplicada (CPA): Excepcional, Escolar, Ludoterapia, Psicomotricidade, Organizacional, Terceira Idade, etc.; elaborar em grupo, um Projeto de Educação Sexual, de preferência atendendo as expectativas da instituição em que deseja trabalhar (Escola, Empresa, Hospital, Comunidade, etc.), juntamente com a elaboração de uma pesquisa; redigir relatórios para todas as atividades práticas a fim de que o supervisor acompanhe o registro das atividades, depois arquivadas nas pastas do CPA; e entrega no final do semestre do Relatório Final de Estágio (Relatório Final de atendimento de clientes do CPA ou Relatório Final do Projeto de Intervenção e Pesquisa desenvolvido).

d) Avaliação: Para avaliação do aluno no estágio, o supervisor estará observando todos os aspectos éticos e teórico-práticos de sua formação: aproveitamento da literatura pesquisada (conteúdo e repertório adequado); capacidade de articulação entre os aspectos teóricos e a atuação prática; assiduidade, responsabilidade no cumprimento dos prazos das tarefas; entrega de relatórios parciais para correção pelo supervisor; entrega do relatório final ao término do estágio que fica sob os cuidados do supervisor (Arquivo de projetos) para futuras consultas ou publicações.

e) Periodicidade e Cronograma: As supervisões acontecerão semanalmente. Em cada supervisão, deverá ocorrer a discussão das leituras, a supervisão dos casos e a análise dos projetos. 


\section{CONSIDERAÇÕES FINAIS}

A idéia inicial da proposta de inserção de Disciplinas de Sexualidade no Curso de Formação de Psicólogos da atual UNESP/Campus de Bauru/SP foi fruto de uma luta da Prof ${ }^{a}$ Ms. Márcia Faria de Castro ${ }^{3}$. Uma nova proposta, então revisada e ampliada por esta autora, tem sido implantada desde o primeiro semestre de 1996. A avaliação qualitativa desta experiência têm sido realizada através dos relatos verbais dos alunos, avaliações finais (por escrito) das duas turmas de alunos (integral e noturno) em cada semestre. A avaliação quanto à satisfação dos objetivos, ementas e conteúdos atendidos em ambas as disciplinas tem tido, em geral, porcentagens entre $90 \%$ e $100 \%$ de 'plenamente satisfatória'. A maioria dos alunos considera as disciplinas como 'ótimas', 'atuais' e 'importantes para a formação profissional'. Acrescente-se, porém, após as avaliações dos alunos, da docente responsável e de sua constante atualização teórica, ou seja, após as experiências decorridas em cada disciplina, as propostas das disciplinas - objetivos, ementas, conteúdos, metodologia, referências bibliográficas, etc. - são continuamente revisadas.

Vale ressaltar que as disciplinas relativas à sexualidade humana têm relação e articulam conteúdos com muitas outras disciplinas do Curso como: Antropologia, Filosofia, Psicologia do Desenvolvimento, Psicologia da Personalidade, Psicologia das Relações Humanas, Didática e Prática de Ensino, dentre outras ${ }^{4}$. A oportunidade dos alunos participarem de projetos de orientação sexual mais prolongados e sistematizados no decorrer de um Estágio em Educação Sexual, oferece aos alunos a possibilidade concreta de organizarem, planejarem, executarem e avaliarem projetos de intervenção, baseados nos conhecimentos teóricos, e também expandirem o treino de desenvolvimento em pesquisa (iniciação científica).

Reitere-se que a importância de se incluir o tema da sexualidade humana nos cursos de graduação vai além das questões específicas referentes ao papel profissional do psicólogo, como por exemplo o exercício de Terapeuta Sexual. Embora todos os aspectos das disciplinas mereçam um aprofundamento teórico-prático, caso o aluno deseje trabalhar nestas questões após a sua formação é fundamental que seja garantida uma reflexão sobre os temas da sexualidade humana na graduação. Pensamos que em

3. A autora faz questão de registrar um agradecimento especial à Professora Ms. Márcia Faria de Castro, atualmente aposentada da UNESP, pelo respeito, gratidão e carinho que sente por aquela que the ensinou o ofício do estudo da sexualidade humana e que the possibilitou a responsabilidade e o prazer de assumir e aprender a arte de uma docência ética, refletindo e debatendo dogmas e preconceitos.

4. À respeito desta última, a articulação tem sido tão bem estabelecida que muitos projetos de estágio em Pratica de Ensino - Licenciatura (ministrado pelos graduandos para cumprimento obrigatório das cargas de horário de estágio nas escolas de primeiro e segundo graus) foram referentes às questões da sexualidade humana, estudadas nas disciplinas. 
todas as demais áreas de atuação do psicólogo ele pode e deve atuar como um educador sexual, uma vez que a sexualidade humana faz parte da vida, de toda individualidade e personalidade e é inerente aos seres humanos, e à sociedade em geral.

\section{REFERÊNCIAS BIBLIOGRÁFICAS}

ALBERONI, F. Enamoramento e amor. Rio de Janeiro: Rocco, 1994.

BARROSO, C.; BRUSCHINI, C. Sexo e juventude - como discutir a sexualidade em casa e na escola. São Paulo: Cortez, 1991.

CAMPOS, D.M.S. Psicologia da adolescência; Petrópolis: Ed. Vozes, 1987.

CHAUÍ, M. Repressão Sexual - essa nossa (des)conhecida. São Paulo: Ed. Brasiliense, 1984.

CAVALCANTI, R. (coord.) Saúde sexual e reprodutiva -Ensinando a ensinar. Brasília: CESEX s/d.

FAGUNDES, T. C. P. C. Educação Sexual-prós e contras. Em Revista Brasileira de Sexualidade Humana, v. 3, nº 2, 1992. . Implantação da disciplina sexualidade e educação na Universidade Federal da Bahia. Revista Brasileira de Sexualidade Humana. Vol. 7 (2): 131-134, 1996.

GOLDBERG, M.A. Educação Sexual, uma proposta um desafio. São Paulo: Cortez, 1988.

GTPOS. Sexo se aprende na escola. São Paulo: Olho Dágua, 1995.

GTPOS; ABIA; ECOS. Guia de Orientação Sexual - Diretrizes e Metodologia. São Paulo: Casa do Psicólogo, 1994.

GUIMARÃES, C.R.P. O descaso em relação à educação sexual na escola: estudo de manifestações de futuras professoras de $1^{\underline{a}}$ à $4^{a}$ série do $1^{\circ}$ grau. São Carlos, UFSCar, 1992.

KAPLAN, H. S. A nova terapia do sexo. Rio de Janeiro: Nova Fronteira, 1974.

MANNOCCI, J. F. \& col. Disfunções Sexuais - abordagem clínica e terapêutica. São Paulo: Ed. BYK., 1995.

MASTERS, W. H. \& JOHNSON, V. E. A Inadequação Sexual Humana. São Paulo: Roca, 1985.

REVISTA BRASILEIRA DE SEXUALIDADE HUMANA, Vários autores. SBRASH. São Paulo: Editora Iglu.

RIBEIRO, M. (Org) Educação Sexual: novas idéias, novas conquistas. Rio de Janeiro: Ed. Rosa dos Tempos, 1993.

RIBEIRO, P. R. M. Educação Sexual além da Informação. Temas Básicos de Educação e Ensino. São Paulo: EPU, 1990.

SÃO PAULO (Estado) Secretaria da Educação. Coordenadoria de Estudos e Normas Pedagógicas. Sexualidade Humana, reflexões e proposta em ação. São Paulo. SE/CENP, 1986.

SERAPIÃO, J. J.; SILVA, M. C. A. Disciplinas de sexualidade humana para os cursos de graduação em medicina e enfermagem da Universidade Gama Filho RJ. 1. Projeto de implantação. Revista Brasileira de Sexualidade Humana. Vol. 7 (2): 135-145, 1996. 
SUPLICY, M. Conversando sobre sexo. Petrópolis: Vozes, 1983. . Papai, mamãe e eu. São Paulo: FTD, 1990.

VITIELLO, N. Sexologia. Comissão de Sexologia da FEBRASCO. São Paulo: Ed. Rocca, 1986.

. Outra vez a educação sexual. Boletim Informativo da Sociedade Brasileira de Sexualidade Humana. São Paulo, 4 (1), 1992.

. Reprodução e Sexualidade - um manual para educadores. São Paulo: CEICH, 1994.

Sexualidade quem educa o educador - um manual para jovens, pais e educadores. São Paulo: Iglu, 1997.

TIBA, I. Adolescência-o despertar do sexo. São Paulo: Ed. Gente, 1994.

. Puberdade e Adolescência- desenvolvimento biopsicossocial. São Paulo: Ed. Agora, 1986. 